\title{
Current and Future Treatment of Hepatocellular Carcinoma: An Updated Comprehensive Review
}

\author{
Saleh Daher, Muhammad Massarwa, Ariel A. Benson and Tawfik Khoury* \\ Gastroenterology and Liver Units, Department of Medicine, Hadassah-Hebrew University Medical Center, Jerusalem, Israel
}

\begin{abstract}
Hepatocellular carcinoma (HCC) is among the leading causes of cancer-related mortality. The principal treatment is surgical resection or liver transplantation, depending on whether the patient is a suitable transplant candidate. However, in most patients with HCC the diagnosis is often late, thereby excluding the patients from definitive surgical resection. Medical treatment includes sorafenib, which is the most commonly used systemic therapy; although, it has been shown to only minimally impact patient survival by several months. Chemotherapy and radiotherapy are generally ineffective. Due to the poor prognosis of patients with HCC, newer treatments are needed with several being in development, either in preclinical or clinical studies. In this review article, we provide an update on the current and future medical and surgical management of HCC.
\end{abstract}

Citation of this article: Daher S, Massarwa M, Benson AA, Khoury T. Current and future treatment of hepatocellular carcinoma: an updated comprehensive review. J Clin Transl Hepatol 2018;6(1):69-78. doi: 10.14218/JCTH.2017.00031.

\section{Introduction}

Hepatocellular carcinoma (HCC) is currently the sixth most common cancer worldwide, and considered to be the second deadliest cancer for men and sixth for women; according to GLOBOCAN, in 2012 it was estimated that 745,517 deaths were a direct result of HCC. ${ }^{1-4} \mathrm{HCC}$ development, in most cases, arises in the setting of underlying end-stage liver disease, secondary to either viral hepatitis (specifically hepatitis B virus (HBV) or hepatitis C virus) or other non-viral chronic liver diseases. ${ }^{5,6}$ Given its asymptomatic nature in the early stages of the disease, the majority of HCC cases

Keywords: HCC; Treatments; Sorafenib; Mortality.

Abbreviations: ALPPS, Associated Liver Partition and Portal vein ligation for Staged hepatectomy; BCLC, Barcelona Clinic Liver Cancer; CTLA-4, cytotoxic T-lymphocyte-associated protein 4; EASL, European Association for the Study of the Liver Disease; FDA, Food and Drug Administration; FLR, future liver remnant; HBV, hepatitis B virus; HCC, hepatocellular carcinoma; HIFU, highly-focused ultrasound; IRE, irreversible electroporation; MWA, microwave ablation; PD-1, programmed cell death protein 1; PDL-1, programmed cell death protein 1; PEIT, percutaneous ethanol injection therapy; RFA, radiofrequency ablation; SIRT, selective internal radiation therapy; TACE, trans-arterial chemoembolization; UCSF, University of California San Francisco; VEGF, vascular endothelial growth factor.

Received: 12 May 2017; Revised: 7 October 2017; Accepted: 23 October 2017 *Correspondence to: Tawfik Khoury, Institute of Gastroenterology and Liver diseases, Hebrew University-Hadassah Medical Center, P.O.B. 12000, Jerusalem IL-91120, Israel. Tel: +972-509870611, E-mail: tawfikkhoury1@hotmail.com are detected in advanced stages, leading to incurable disease states. ${ }^{7}$ Currently, sorafenib is the only approved systemic medication for the treatment of advanced HCC, in addition to other several medical and surgical treatment options (Fig. 1); however, there is a great unmet need for new effective therapies for this condition.

\section{Genetic aberrancy in HCC}

In vitro, $\mathrm{HCC}$ cells have been shown to be associated with several chromosomal genetic alterations. To date, several aberrant genes encoding proteins have been identified and implicated in HCC pathogenesis, including P53, P16, P73, APC, PTEN, IGF-2, BRCA2, SMAD2, SOCS, beta-catenin, retinoblastoma proteins, c-myc and cyclin D1 proteins. ${ }^{8-10}$ P53 is considered as one of the most common mutated genes that is expressed in HCC, from among these genes mentioned. ${ }^{11}$ Other than the specific genetic mutation in HCC, there are several involved signaling/angiogenetic pathways observed in HCC development, including vascular factors produced by tumor cells themselves, growth factors and oncogene receptors. For example, HCC overexpresses epidermal growth factor, which stimulates tyrosine kinase receptor that in return stimulates cell surface signal transmission to the nucleus.

Another similar mechanism that underlies HCC development involves MAPK pathway activation acting through the Ras protein. The Ras protein undergoes activation via phosphorylation, which allows the delivery of signals to the nucleus via downstream components of the pathway, such as ERK1, RAF and MEK. ${ }^{12,13}$ As mentioned above, HCC is a highly-vascularized tumor with strong angiogenetic activity that is enriched with vascular endothelial growth factor on the surface of tumor cells. Thus, the vascular endothelial growth factor (VEGF) pathway has also been targeted as a treatment for HCC. ${ }^{12}$

\section{HCC epigenetics}

Several epigenetic factors underlie the progression of HCC, including invasion, distant metastasis and hematological dissemination. Epigenetics are related to heritable phenotypic change that does not relate to changes of the genome but rather changes that may result from environmental factors, or other developmental factors. Epigenetic alterations that have been reported in HCC include DNA hyper-/ hypo-methylation, histone disruption and non-coding RNAs as manifested by altered expression of mirco-RNAs. ${ }^{14,15}$ Those epigenetic changes can be used for diagnostic purposes, as well for prognosis. For example, liver specific DNA methylation can guide the clinician for early urgent screening 


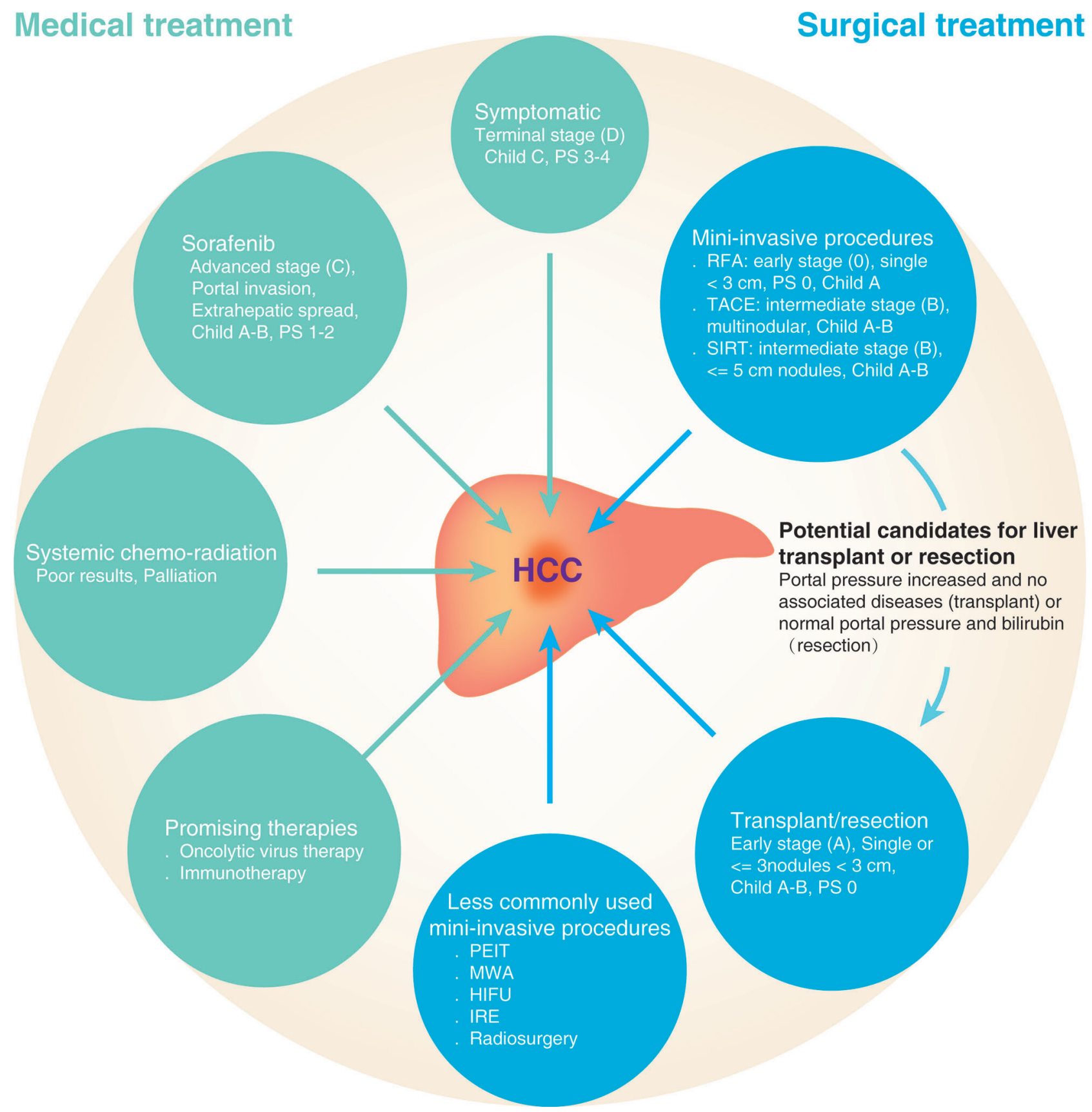

Fig. 1. Summary of the available medical and surgical treatment options for HCC.

for HCC in cirrhotic patients. ${ }^{16}$ Furthermore, under-expression of miR-122 was associated with poorer prognosis in HCC patients. ${ }^{17}$ Similarly, histone modifying genes (EZH2 and SUV39HZ) and protein produced by histone phosphorylation (ARK1 and ARK2) were all poor predictors of outcome and invasiveness. ${ }^{18,19} \mathrm{~A}$ recent study by Mansour et al. ${ }^{20}$ found that hypermethylation of RASSF1A positively correlated with increased tumor size but not with alpha-fetoprotein level, and aggravated the hepatocarcinogenic process; the authors suggested the incorporation of RASSF1A measurement as a screening tool in patients at risk for HCC development.
All those epigenetic biomarkers are promising targets in HCC that may provide clinicians with better diagnostic and prognostic tools; and, in the future, epigenetic-directed therapy might be developed.

\section{Former and current medical treatment}

\section{Sorafenib}

The development of targeted therapies for HCC has been ongoing for many years, leading to the development of sorafenib in 1990. Due to the dearth of medical therapy for 
Daher S. et al: Update on HCC treatment

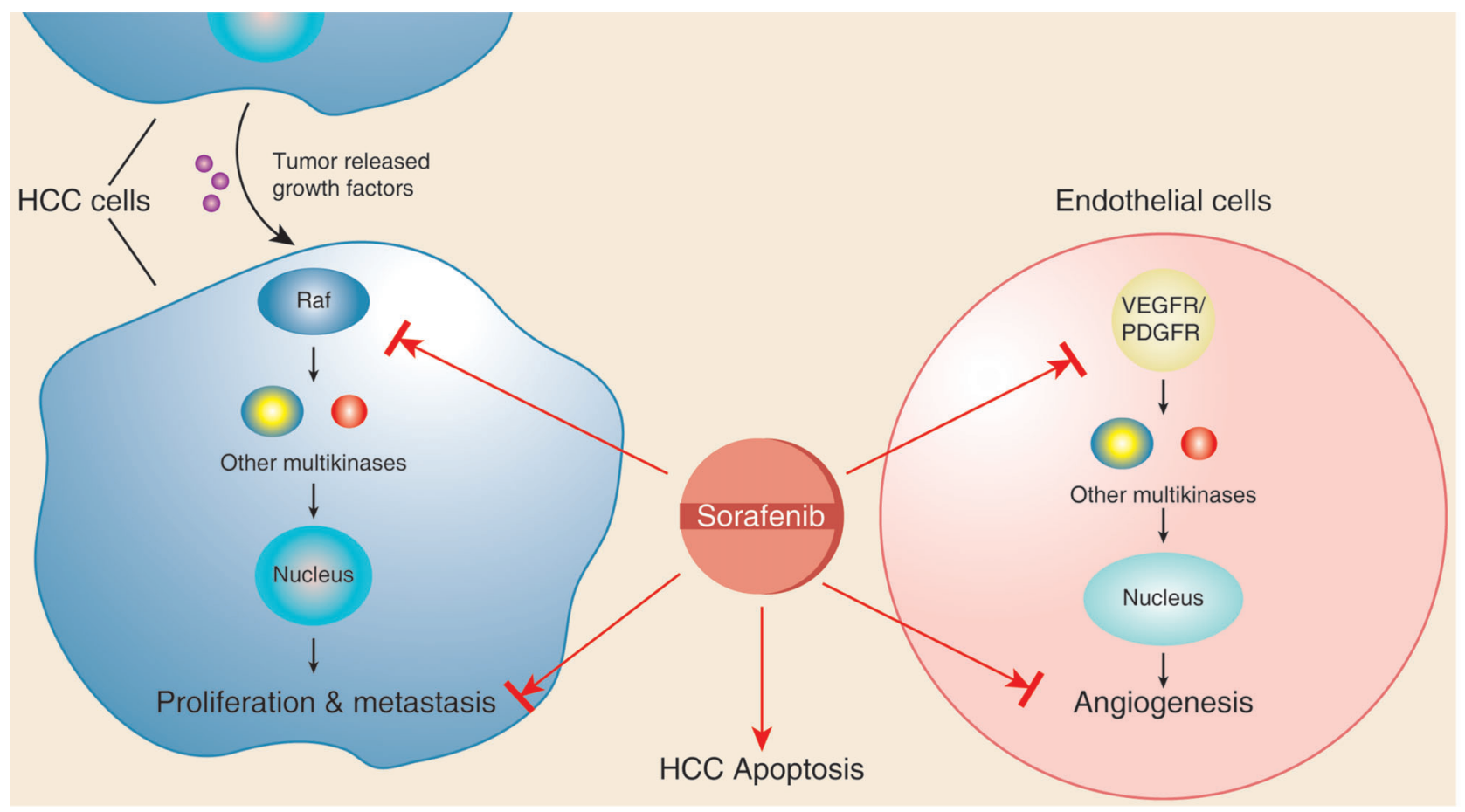

Fig. 2. Mechanism of action of sorafenib. Sorafenib inhibits the action of tyrosine kinase Raf and other factors involved in vasculogenesis (vascular endothelial growth factor receptor and platelet-derived growth factor receptor), which in turn inhibits activation of other downstream multikinases that are normally essential for cell growth, angiogenesis, proliferation and metastasis of HCC cells.

HCC, sorafenib was rapidly approved by the Food and Drug Administration (FDA), irrespective of the degree of cirrhosis. ${ }^{21}$ Sorafenib is an oral multi-kinase inhibitor that inhibits cell proliferation through a strong inhibition of the serine/threonine kinase RAF. Moreover, it was shown to inhibit pro-angiogenic VEGF and platelet-derived growth factor receptor (Fig. 2). 22,23 Sorafenib was initially approved by the FDA for treatment of metastatic renal cell carcinoma, and later it was approved for management of HCC and metastatic differentiated thyroid carcinoma. ${ }^{24}$

The efficacy of sorafenib has been demonstrated in several studies. In the SHARP randomized controlled trial, the overall survival in the sorafenib treatment group was 10.7 months, as compared to 7.9 months of the placebo group, with a good safety profile in HCC patients, ${ }^{25}$ making sorafenib the only approved systemic agent for the treatment of advanced HCC. There is a great unmet need for new, effective therapies for this condition. However, even though sorafenib is currently regarded as the best option in advanced HCC, it is only able to prolong survival for a few months.

\section{Systemic chemotherapy and radiotherapy}

Previously, HCC was treated with chemotherapy and radiotherapy. However, the reported literature has shown poor results associated with those treatment options. Thus, their use is still controversial and only applicable in the context of palliative treatment. HCC is traditionally considered as a highly chemo-resistant tumor. However, conventional chemotherapy is still considered for palliation therapy, which may improve the patient's quality of life. Among the chemotherapeutic drugs used in HCC, doxorubicin is one of the most commonly used, even though in up to $90 \%$ of cases it did not show response and it did not improve survival partial. Other commonly used chemotherapeutic drugs include 5-fluorouracil in combination and cisplatin either alone or in combination therapy. ${ }^{8,26}$ Overall, other investigated chemotherapeutic drugs, such as capecitabine, mitoxantrone, placlitaxel, gemcitabine and irinotecan, have failed to show promising results. ${ }^{27-29}$

Similar to that seen with chemotherapy, HCC is radiotherapy-resistant and treatment with systemic radiotherapy plays only a minor role in HCC cases. The diverse genetic aberration in HCC, as well as the expression of the P53 gene and other genes and/or proteins involved in cell death and proliferation pathways, might provide the basis for the development of resistance for radiation. ${ }^{30,31}$ Systemic radiotherapy is still used for palliative therapy of HCC metastasis.

\section{Current and future medical treatments}

Recently, researchers have focused on the development of HCC-targeted medications. For example, several drugs have been developed targeting angiogenesis, such as sunitinib, brivanib, linifanib, vatalanib, TSU-68, cediranib, bevacizumab and ramucirumab. ${ }^{32}$ Several other therapies were also under development, including epidermal growth factor receptor inhibitors erlotinib and lapatinib, MEK1/2 competitive inhibitor (selumetinib), mTOR antagonist (everolimus) and multikinase inhibitors (nintedanib and regorafenib). However, all of these medications are still in pre-clinical and early clinical studies and none of them have been yet been shown to be effective or approved for HCC treatment. ${ }^{32}$

\section{Oncolytic virus therapy}

Recently, more attention and research efforts has been put forth towards oncolytic virus therapy, a promising new 


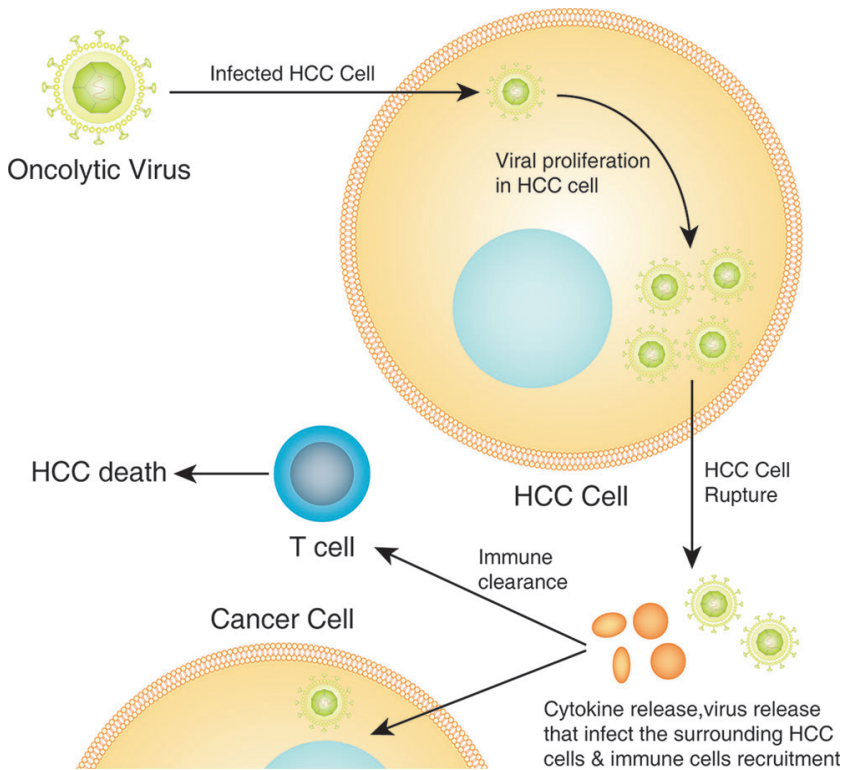

Fig. 3. Mechanism of action of oncolytic virus therapy. After HCC-induced oncolytic virus infection, the virus multiplies within the HCC cells, leading to cell rupture and release of second-generation viruses that infect the surrounding $\mathrm{HCC}$ cells, as well to cytokines release which in turn activate the antitumor immune response by recruitment of immune cells (innate and adaptive immune system) that lead to immune clearance and HCC apoptosis.

therapeutic approach for cancer treatment. This treatment strategy is defined as a genetically engineered or naturally occurring virus that can kill cancer cells by activating the immune system, subsequently combating the cancerous cells without harming the normal tissues (Fig. 3). Recent studies have shown that the administration of a second-generation oncolytic herpes simplex virus-type 1 with granulocyte macrophage colony-stimulating factor into malignant melanoma lesions suppresses tumor growth and progression, which was associated with an overall survival benefit.

The second-generation oncolytic human simplex virus type- 1 is the first oncolytic virus therapy approved in both the USA and Europe. Clinical studies are being performed in several oncolytic viruses, including vaccinia virus JX-594 (pexastimogene devacirepvec) for HCC, granulocyte macrophage colony-stimulating factor-expressing adenovirus CG0070 for bladder cancer, and Reolysin (pelareorep), a wild-type variant of reovirus, for head and neck cancer; and, in Japan, a phase II clinical trial of a third-generation oncolytic human simplex virus type- 1 in glioblastoma patients is still ongoing. Interestingly, oncolytic virus therapy seems to be the anticipated breakthrough in cancer therapy generally and in HCC specifically. ${ }^{33}$

\section{Immunotherapy}

The immune system is a crucial player in the combat against malignancies. Since its introduction into clinical practice, immunotherapy has revolutionized cancer treatment. Two checkpoint inhibitors have been developed for cancer treatment, the cytotoxic T-lymphocyte-associated protein 4 (CTLA-4) and the programmed cell death protein 1 pathway (PD-1/PD-L1); this approach is now considered as a cornerstone treatment regimen in cancer therapy. The first CTLA-4 inhibitor was ipilimumab, which showed a significant survival benefit in patients with advanced melanoma, ${ }^{34}$ which led to its approval by the USA FDA in 2011.

In HCC, immune tolerance is present owing to several immunosuppression mechanisms that lead to augmented inhibitory checkpoint molecules. Among those signals that lead to immune tolerance are CTLA- $4,{ }^{35}$ PD-1 and its ligand (PD-L1), ${ }^{36}$ lymphocyte-activation gene $3,^{37}$ and T-cell membrane protein 3 and its ligand (galectin-9). ${ }^{38}$ A recent study reported overexpression of lymphocyte-activation gene 3 in HBV patients, and showed it to cause a reduction in CD8+ $\mathrm{T}$ lymphocyte infiltration of HCC. ${ }^{37}$ Moreover, Li et al. ${ }^{38}$ showed that targeting of the T-cell membrane protein 3/galectin-9 pathway can be an effective potential therapy of HCC related to HBV.

Several preclinical and clinical studies have been published regarding immunotherapy in HCC. Chen et al. ${ }^{39}$ showed that administration of CTLA-4 inhibitor augments antitumor immunity in a murine $\mathrm{HCC}$ model, with a tumor rejection rate of $90 \%$ and a curative rate of $50 \%$ in metastatic HCC. Another clinical study reported a partial response of $17.6 \%$ and disease control of $76.4 \%$ of CTLA-4 inhibitor (tremelimumab) in patients with hepatitis $C$ virus-associated HCC with Child-Pugh grades $A$ and $B$ who failed traditional HCC therapy. ${ }^{40}$ In that study, the most common side effects were fatigue and anorexia, which occurred in almost one-half of patients, and a transient elevation of liver enzymes mainly after the first dose of therapy.

Similar to CTLA-4 inhibitor, PD-1/PDL-1 has been investigated in several studies. PD-1/PDL-1 is mainly found on $\mathrm{T}$ and $\mathrm{B}$ lymphocytes, T-regulatory cells and natural killer cells. This molecule mediates $T$ cell function inhibition, thus inhibiting tumor cell apoptosis. ${ }^{41,42} \mathrm{~A}$ recent study has shown an association of increased disease progression and poorer prognosis with intra-tumor and circulating PD-1/PDL-1 in patients with HBV. ${ }^{36}$ Similarly, Gao et al. ${ }^{43}$ have shown a poor prognosis of HCC with high intra-tumor expression of PD-1/PDL-1, as compared to low-level expression. Moreover, PDL-1 overexpression was the most important independent factor for postoperative recurrence on multivariate analysis. A recent published large multicenter study which evaluated nivolumab, a fully human IgG4 monoclonal PD-1 inhibitor antibody, in patients with histologically-proven advanced HCC showed overall effective antitumor activity and tolerated safety profile. ${ }^{44}$

\section{Surgical treatments: minimally invasive procedures}

In cirrhotic patients with HCC who are not candidates for major surgical therapeutic procedures, minimally invasive procedures, including radiofrequency ablation (RFA), transarterial chemoembolization (TACE), highly-focused ultrasound (HIFU), microwave ablation (MWA) and irreversible electroporation (IRE), can be offered. These techniques are performed with imaging control, and maximum efficiency for nodules is less than $3 \mathrm{~cm}$ of diameter, for which the complete response rate is around $80 \%$. However, a high number of recurrences has been reported with those techniques. ${ }^{45,46}$

\section{TACE}

TACE has been indicated as the first treatment option for intermediate HCC patients with Barcelona Clinic Liver Cancer (BCLC) stage B. ${ }^{46,47}$ TACE mediates its antitumor effect by 
local catheter-guided administration of chemotherapeutic agents mixed with lipiodol which cause selective HCC targeted blood supply embolization and subsequent ischemia and tissue necrosis. ${ }^{1,48}$ Furthermore, TACE has been used as a bridging therapy for HCC patients awaiting liver transplantation, in order to prevent further tumor progression, thus maintaining the eligibility criteria for liver transplantation. ${ }^{49}$ TACE has been associated with 2 -year survival benefit $(\mathrm{HR}=0.53,95 \% \mathrm{CI}$ : $0.32-0.89 ; p=0.017) .50$

Recent large meta-analysis ( 9 randomized controlled trials were included) showed overall improved survival compared to symptomatic treatment ( $\mathrm{HR}=0.705,95 \% \mathrm{CI}: 0.5-0.99) .{ }^{51}$ However, TACE has been associated with adverse events, commonly post-embolization syndrome which is characterized by abdominal pain, elevated temperature and elevated liver enzymes at 1-2 days following the procedure. ${ }^{52}$ Other adverse events include iatrogenic bile duct injury, hypoxic cholecystitis and liver abscess. ${ }^{53}$ Moreover, TACE-related mortality has been reported in approximately $0.38 \%$, according to recent study. ${ }^{54}$ However, in an advanced cirrhosis stage, liver function deterioration can develop, and in one study $17.3 \%$ of patients with cirrhosis and ascites developed post-procedural liver failure, with $94 \%$ of patients dying within 1 year following TACE. ${ }^{55}$

\section{RFA}

The first application of RFA was in 1990, and FDA approval was obtained in 2001. ${ }^{56,57}$ Currently, RFA is the most commonly applied minimally invasive treatment for advanced HCC. RFA delivers a rapid electromagnetic pulse that causes thermal injury leading to coagulative necrosis of the tissue. The heat injury is dependent on both the temperature achieved and the duration of heating. Recently, beneficial results have been demonstrated by RFA in local advanced HCC.

Currently, RFA is considered as one of the main treatments of $\mathrm{HCC}$ and it can achieve complete response rates in about $90-100 \%$ of $\mathrm{HCC}$ lesions below $3 \mathrm{~cm}$, with the ability to obtain clear surgical margins. It is considered as an effective alternative for surgical resection in operable BCLC $0-1$, according to the European Association for the Study of the Liver disease (EASL)- European Organization for Research and Treatment of Cancer. ${ }^{58}$ Moreover, there are reports that RFA can be used to hinder the progression of HCC until liver transplant. ${ }^{59}$ Recently, the international recommendation is not to treat $\mathrm{HCC}$ by RFA when the HCC size exceeds $5 \mathrm{~cm} .^{23,60}$

The RFA safety profile is high, as it is associated with minor side effects in about $5 \%$ and all of them are self-limited. However, mortality and major complications have been reported in $0.3 \%$ and $2 \%$ with RFA, respectively, including biliary tree injury, hemorrhage, hepatic abscess and intestinal perforation. ${ }^{61}$ Another worrisome complication that was reported in almost $0.5 \%$ is tumor seeding during the time of needle withdrawal; however, this complication can be prevented by application of low-grade heat in the tract at the time of withdrawal of the needle.

\section{Percutaneous ethanol injection therapy (PEIT)}

PEIT is one of the most common chemical ablation techniques for HCC patients who are not candidates for surgery and who have BCLC stage $0-A{ }^{62}$ It is still commonly used, given its low cost and technical simplicity. Ethanol is a cytotoxic material that causes tumorous tissue necrosis, as well tumor microcirculation thrombosis and resultant ischemia. The destructive effect of alcohol is effective due to the extensive vascularity and soft consistency of HCC, which enables the alcohol to diffusely penetrate the tumor tissue. ${ }^{63}$

PEIT is mostly used in small HCC, at which the necrosis rate of $\mathrm{HCC}$ less than $2 \mathrm{~cm}$ can reach $90-100 \%$, while the rate decreases to about 70\% in HCC of more than $2 \mathrm{~cm}$ and less than $3 \mathrm{~cm} .{ }^{46}$ Ethanol injection requires multiple injections on separate days and rarely induces significant necrosis in tumors more than $3 \mathrm{~cm}$, largely because the injected ethanol rarely reaches the entire tumor volume. In one study, PEIT was effective in only $50 \%$ of patients with multinodular or large $(3-5 \mathrm{~cm}) \mathrm{HCC}$; in addition, tumor progression was seen in almost $33 \%$ of $\mathrm{HCC}$ of more than $3 \mathrm{~cm}$ despite several treatment courses. ${ }^{64}$

HCC size is a very important factor in the selection of locoregional therapy, such as RFA. The American Association for the Study of Liver Disease guidelines state that in HCC less than $2 \mathrm{~cm}$, the efficacy of RFA and PEIT is similar, while in tumors more than $2 \mathrm{~cm}$, RFA benefits outweigh PEIT. ${ }^{46}$ PEIT is associated with minor side effects and mostly is well tolerated. ${ }^{65}$ The 1 - and 5 -year survival rates with PEIT are reported to be $64 \%-100 \%$ and $32 \%-59 \%$, respectively. 66 Furthermore, the presence of septa within the tumor is important as it inhibits the diffusion capacity of ethanol into the tumorous tissue, which reduces the probability of achieving complete response. Thus, tumor size and structure are very crucial to accurate determination and are a perquisite for decision-making in PEIT treatment.

\section{MWA}

Thermo-ablative treatment for HCC has also been reported. MWA consists of electromagnetic waves that range from 1-300 GHz. It can be performed by several routes, including intraoperatively, laparoscopically and percutaneously. MWA has some advantageous features over RFA, including higher temperature degree being transmitted to the target tissue, shorter duration of treatment session and the absence of skin burning risk. Earlier randomized controlled trials that aimed to compare RFA versus MWA reported similar efficacy of the two therapeutic methods; however, RFA was slightly superior to MWA in terms of local tumor control and relatively lower rate of complications. ${ }^{67}$ Moreover, a recent large study involving more than 1000 patients with malignant hepatic tumors which were treated by MWA reported a major complication rate of $2.6 \%$ and with higher minor complication rate, including pain, fever, pleural effusion and skin burns. ${ }^{68}$

\section{HIFU}

HIFU is another noninvasive technique used for the treatment of unresectable HCC, intended to deliver mechanical energetic waves to a targeted volume of HCC and causing tissue destruction by local heat waves. HIFU has been used in the management of benign prostatic hypertrophy and inoperable prostatic cancer ${ }^{69,70}$ and in uterus myoma. ${ }^{71}$ Furthermore, HIFU has shown efficacy in treating liver malignancies in both animal and human studies. ${ }^{72,73}$ The mechanism involves the ultrasound initiating vibrating particles longitudinally and transversally to the direction of spreading. When ultrasound waves are focused to reach high acoustic densities (100$10,000 \mathrm{~W} / \mathrm{cm}^{2}$ ), which rapidly raises local temperature to at 
least 56 degrees Celsius and above, this leads to parenchymal necrosis induced by heat shock in few seconds. ${ }^{74}$

The typical HIFU transducer generates a cylindrical focus with a diameter of $1.5 \mathrm{~mm}$ and a length of $1 \mathrm{~cm}$ in the direction of the wave. Adjacent to the focus, the temperature decreases rapidly, leading to histologically clearly-defined tissue coagulation. ${ }^{75}$ Several limitations are related to this method, including the delivery of small size of focus volume, necessitating multiple treatment sessions. Another limitation is the formation of microbubbles when high acoustic intensities are used, which interfere with the acoustic field.

Still, large randomized trials are needed before any conclusion can be made in the utility for clinical practice.

\section{IRE}

IRE was mainly used as electro-chemotherapy to affect the cell membrane permeability. IRE acts by generating very short electrical pulses that cause loss of membrane potential in human cells by destabilizing them, which subsequently causes formation of larger holes in the cell membrane that finally lead to cell death. Currently, IRE is extensively used in water decontamination and sterilization or preprocessing use; recently, its use in killing of tumor cells has been reported. The IRE technique has the ability to delineate the tumor borders by accurately applying electrical pulse to the tumorous tissue without affecting the adjacent healthy parenchyma; thus, the structures in proximity to the destroyed tissue by IRE are preserved. ${ }^{76-78}$

\section{Selective internal radiation therapy (SIRT)}

More recently, SIRT has been developed for use in HCC patients who are ineligible for other therapies, and specifically in cases such as lesions more than $7 \mathrm{~cm}$ in diameter, with vascular invasion and failure of prior TACE. In this technique, HCC are targeted via injection of microspheres, which are labelled with $\beta$-emitting radioisotope, such as 90Yttrium, which then delivers the radiation to the liver tumor. ${ }^{79}$ Several studies have been performed and reported various responses, including partial response, complete response and stable disease.

Salem et al. ${ }^{80}$ reported treatment with 90Yttrium in a single-center, prospective, longitudinal cohort study of 291 HCC patients. The 30-day mortality rate was 3\%. Response rates were $42 \%$ and $57 \%$ based on World Health Organization and EASL criteria, respectively. The overall TTP was 7.9 months (95\%CI, 6-10.3). Survival times differed between patients with Child-Pugh $A$ and $B$ disease ( $A, 17.2$ months; $\mathrm{B}, 7.7$ months; $p=0.002) .{ }^{80}$ Another study by Hilgard et al. ${ }^{81}$ reported complete response in $3 \%$ of patients, partial response in $37 \%$, stable disease in $53 \%$, and primary progression in $6 \%$ of the patients with $\mathrm{HCC}$; the median overall survival was 16.4 months. Another study showed no differences between SIRT and drug-eluting bead TACE. ${ }^{82}$

Several adverse events have been associated with SIRT, including radiation pneumonitis and pulmonary fibrosis in the setting of hepato-pulmonary shunts. ${ }^{83}$ Furthermore, SIRT may cause gastrointestinal ulceration. The most common complication is post-radioembolization syndrome, which includes abdominal pain, nausea and fatigue. Fever is mostly transient, lasting up to 1 month after SIRT. ${ }^{84}$

It is important to accurately select HCC cases for SIRT as it was shown to be associated with radioembolization-induced liver disease, which is characterized by symptoms of liver failure in the absence of HCC progression. This syndrome arises from 1-2 months following procedures and is characterized by ascites and reduced liver function. ${ }^{84}$ Other less frequently reported adverse events include post-SIRT cholecystitis, abscess and bilioma, which occur in less than $2 \%$ of cases. $^{85}$

In conclusion, SIRT is a promising treatment option for advanced unresectable HCC cases.

\section{Sorafenib combined with TACE}

The administration of conventional TACE led to increased survival rates of $80 \%, 43 \%$ and $23 \%$ at a time frame of 1,3 , and 5 years, respectively. ${ }^{86}$ Still, TACE limitation is the highest restriction rate, possibly due to the up-regulation of VEGF and platelet-derived growth factor receptor in hepatic tissues which consequently aggravates the process of angiogenesis. However, a prospective single-center study by Pawlik et $a l .{ }^{87}$ which examined the application of combined TACE with doxorubicin-eluting beads and sorafenib in patients with advanced HCC showed a disease control rate of $95 \%$, according to Response Evaluation Criteria in Solid Tumors Group, and $100 \%$ according to EASL, and an objective response rate of $58 \%$ according to EASL.

Another few clinical trials have shown promising results. Bai et al. ${ }^{88}$ has conducted a prospective nonrandomized controlled trial which compare the efficacy of sorafenib in combination with TACE versus TACE alone for the treatment of patients with unresectable intermediate, or advanced hepatocellular carcinoma. The combination significantly increased the median survival during a follow-up period of 21.4 weeks (7.5 vs. 5.1 months; $\mathrm{HR}=0.61,95 \% \mathrm{CI}: 0.423-0.884 ; p=$ $0.009)$, as compared to the TACE group alone. ${ }^{88}$ Another multicenter retrospective study has shown similar results, with overall median survival being 12 months (95\% CI: $10.1-$ 13.9) in the sorafenib and TACE combination group. ${ }^{89}$ Given these promising data, sorafenib in combination with TACE should be considered for patients affected by advanced HCC.

\section{Radiosurgery}

The concept of radiosurgery was developed by Leksell in $1987 .{ }^{90}$ In this initial version (currently named the Gamma Knife), radiosurgery was used for radiation of brain lesions and upper spine, and recently, a computer assisted radiosurgical technique was developed that enabled treatment administration for other organs, such as liver. ${ }^{91}$ Thus, this CyberKnife System allows the administration of more focused stereotactic radiation based on real-time visualization of the target lesion. The advantage of radiosurgery is that it is capable of administration of radiation therapy to a well characterized tumor with preservation of the surrounding tissue. ${ }^{92}$ Previous studies have reported beneficial CyberKnife treatment for colorectal cancer metastasis. ${ }^{93,94}$ Radiosurgery, as well, might be used as a pre-surgical therapy for down-staging tumors that are not compatible for surgical resection. ${ }^{95}$ Moreover, radiosurgery can be used for preventing tumor growth during liver regeneration after surgical resection for HCC. ${ }^{96}$

Radiosurgery is an effective, feasible therapeutic option. This new emerging therapy is mainly useful for patients who are not eligible for surgery, and particularly for tumor down-staging before surgical procedures such as liver transplantation or 
surgical resection. Further randomized clinical trials are needed to examine the exact prognostic benefits in advanced HCC patients and to more fully delineate the effectiveness of radiosurgery compared to the traditional minimally invasive procedures such as RFA.

\section{Liver Transplantation}

The definitive treatment of HCC is liver transplantation, which allows for both treatment of the underlying liver disease and cure of the HCC. ${ }^{97}$ However, only a small proportion of patients receive a liver due to the strict criteria of liver transplantation in HCC patients (Milan criteria which include patients with one tumor of less than $5 \mathrm{~cm}$ or up to three tumors less than $3 \mathrm{~cm}$ ) and the availability of organs. ${ }^{98}$ The 4-year survival rate of patients within Milan criteria was $75 \% .{ }^{98}$ However, after a liver transplantation the risk of re-infection persists, and approximately half of the patients develop liver cirrhosis post-transplantation. ${ }^{46,99}$

To validate Milan criteria, a recent systemic review of 90 studies that followed 17,780 patients over a 15 -year period identified the Milan criteria as an independent prognostic factor of outcome after orthotopic liver transplantation. ${ }^{100}$ A recent study showed an improved selection of patients with HCC for liver transplantation when adding alpha-fetoprotein and des-gamma carboxyprothrombin into the criteria. ${ }^{101}$ Furthermore, the University of California San Francisco (commonly known as UCSF) has prospectively and retrospectively utilized a newly defined criterion which includes several variables, a single lesion less than or equal to $6.5 \mathrm{~cm}$, or three or fewer nodules with the largest lesion being less than or equal to $4.5 \mathrm{~cm}$ and with a total diameter of less than or equal to $8 \mathrm{~cm}$. The UCSF 1- and 5-year survival rates were $90 \%$ and $75 \%$, respectively. ${ }^{102}$ Similarly, the survival and disease recurrence rates were comparable to those of the Milan criteria. ${ }^{103}$ Another study by Dubay et al. ${ }^{104}$ found an excellent post-liver transplantation rate of any $\mathrm{HCC}$ size and number when aggressive ablative therapies were applied and when the histology ruled out poorly differentiated HCC.

\section{Surgical resection}

In HCC cases without signs of advanced liver fibrosis and portal hypertension, surgical resection is considered the treatment of choice. However, liver surgery in patients with chronic liver disease is associated with an increased risk of hepatic failure, especially after extended resection. Although surgical resection might be a curative option, it is limited by several factors, including high complication rates of blood loss, morbidity and mortality. ${ }^{105} \mathrm{HCC}$ resection is also contraindicated in cirrhotic patients in advanced stages (Child-Pugh scores $\mathrm{B}$ and $\mathrm{C}$ or model for end-stage liver disease over 10). However, recent studies have reported a low mortality rate of less than $5 \%$ in cases of cirrhosis without evidence of portal hypertension. ${ }^{106,107}$

Due to the high rate of disease recurrence, the 5-year survival rates after partial hepatectomy for HCC range between $60 \%$ and $70 \%$. The recurrence rate may be due to the formation of new HCC, or the presence of microvascular invasion or satellite nodules. ${ }^{108,109}$ Currently, the recommendation of EASL and the European Organization for Research and Treatment of Cancer guidelines ${ }^{7}$ state that surgery is restricted to those patients in the very early or early stages of disease (BCLC 0-A). Thus, the best candidates for surgical resection are patients with an isolated liver tumor, absence of radiological evidence of vascular invasion and patients with preserved synthetic liver function. ${ }^{110,111}$

\section{Associated liver partition and portal vein ligation for staged hepatectomy (ALPPS)}

ALPPS is considered as another surgical option for hepatic malignancy. The main advantage of ALPPS is future liver remnant (FLR) induction in short time period. ${ }^{112-114}$ Regenerative capacity is induced by several factors, including hepatic inflow redistribution after portal vein ligation, secretion of several hepato-proliferative factors by liver surgical procedure-induced inflammation that accelerate FLR growth, and transection of bilateral lobes of the liver, preventing collateral circulation formation and further increasing the hepatic inflow to the FLR. ${ }^{115}$ This advantage in ALPPS overcomes the surgical limitations in classic liver surgery, including technical impossibility when the right portal vein is invaded by tumor and unresectability of tumor due to extensive progression. Thus, the ALPPS procedure has achieved increased interest among liver surgeons.

ALPPS is however associated with complications, including biliary leakage and intraperitoneal infection. ${ }^{116}$ Overall mortality rate of $59 \%-64 \%$ and hospital mortality rate of $12-16 \%$ have been seen in association with ALPPS. ${ }^{115}$ Therefore, controversy exists regarding the use of this procedure in real clinical practice. ${ }^{117}$ Furthermore, the overall 90 -day mortality of ALPPS according to the international ALPPS registry was $8.8 \%$, in which $75 \%$ of deaths were related to acute liver failure that appeared following the surgery. Moreover, a model for end-stage liver disease score more than 10 was an independent factor to increased mortality. ${ }^{118}$

In current clinical practice, ALPPS might be considered in several clinical scenarios, as follows: inability of performing the classic conventional surgical approach due to portal vein involvement by HCC; progressive HCC where the risk for tumor progression is high between the two stages of the conventional surgical approach; and, in progressive HCC extension to the vena cava or even right atrium. Contraindications for ALPPS include inoperable hepatic metastasis in the FLR, significant portal hypertension and unresectable extrahepatic metastasis. ${ }^{119}$ Recent studies reported a high perioperative mortality rate of $31 \%$ for most HCC patients. Moreover, the evidence of the oncological endpoints and technical availability of ALPPS is scarce, thus this strategy should be considered in only a highly-selected patient population. ${ }^{120}$ Further studies are needed to examine the exact role of ALPPS in the setting of HCC.

\section{Conclusions}

Hepatocellular carcinoma is an aggressive tumor associated with a poor prognosis. Given its asymptomatic nature in the early stages, HCC is mostly diagnosed at advanced stages, often leading to incurable clinical situations. Current and prior treatment options were only modestly associated with increased survival. In fact, the survival benefit with sorafenib was only for a few months. Nowadays, newly emerging therapeutic targets, as well as new drugs and therapeutic modalities have been investigated in pre-clinical and clinical trials. Until the discovery of curative therapy, or at least drug development with significant survival benefit, clinicians should be careful to screen for HCC in cirrhotic patients and 
diagnosis should be done at early stages, so that if the HCC is identified soon enough for liver transplant, the outcomes will be quite good. Ongoing research should be performed on all potential HCC targets, including at the immunological, molecular and translational levels, in order to reduce the increasing HCC mortality.

\section{Conflict of interest}

The authors have no conflict of interests related to this publication.

\section{Author contributions}

Contributed to the conception and design (TK), data collection, analysis and interpretation, and drafting of the manuscript ( $S D, M M, A A B, T K$ ). All authors approve the final version to be published.

\section{References}

[1] Jemal A, Bray F, Center MM, Ferlay J, Ward E, Forman D. Global cancer statistics. CA Cancer ] Clin 2011:61:69-90. doi: 10.3322/caac.20107.

[2] Venook AP, Papandreou C, Furuse J, de Guevara LL. The incidence and epidemiology of hepatocellular carcinoma: a global and regional perspective. Oncologist 2010;15 Suppl 4:5-13. doi: 10.1634/theoncologist.2010-S4-05

[3] Yang JD, Roberts LR. Hepatocellular carcinoma: A global view. Nat Rev Gastroenterol Hepatol 2010;7:448-458. doi: 10.1038/nrgastro.2010.100.

[4] Ferlay J, Shin HR, Bray F, Forman D, Mathers C, Parkin DM. Estimates of worldwide burden of cancer in 2008: GLOBOCAN 2008. Int J Cancer 2010; 127:2893-2917. doi: 10.1002/ijc.25516.

[5] Singal AG, El-Serag HB. Hepatocellular carcinoma from epidemiology to prevention: translating knowledge into practice. Clin Gastroentero Hepatol 2015;13:2140-2151. doi: 10.1016/j.cgh.2015.08.014.

[6] Gomes MA, Priolli DG, Tralhão JG, Botelho MF. Hepatocellular carcinoma: epidemiology, biology, diagnosis, and therapies. Rev Assoc Med Bras (1992) 2013;59:514-524. doi: 10.1016/j.ramb.2013.03.005.

[7] Finn RS. Emerging targeted strategies in advanced hepatocellular carcinoma. Semin Liver Dis 2013;33:S11-S19. doi: 10.1055/s-0033-1333632.

[8] Brito AF, Abrantes AM, Pinto-Costa C, Gomes AR, Mamede AC, CasaltaLopes J, et al. Hepatocellular carcinoma and chemotherapy: the role of p53. Chemotherapy 2012;58:381-386. doi: 10.1159/000343656.

[9] Alves RC, Alves D, Guz B, Matos C, Viana M, Harriz M, et al. Advanced hepatocellular carcinoma. Review of targeted molecular drugs. Ann Hepatol 2011;10:21-27.

[10] Shearn CT, Petersen DR. Understanding the tumor suppressor PTEN in chronic alcoholism and hepatocellular carcinoma. Adv Exp Med Biol 2015 815:173-184. doi: 10.1007/978-3-319-09614-8_10.

[11] Gomes AR, Abrantes AM, Brito AF, Laranjo M, Casalta-Lopes JE, Gonçalves $A C$, et al. Influence of P53 on the radiotherapy response of hepatocellular carcinoma. Clin Mol Hepatol 2015;21:257-267. doi: 10.3350/cmh.2015. 21.3.257.

[12] Villanueva A, Llovet JM. Targeted therapies for hepatocellular carcinoma. Gastroenterology 2011;140:1410-1426. doi: 10.1053/j.gastro.2011.03. 006.

[13] Delire B, Stärkel P. The Ras/MAPK pathway and hepatocarcinoma: pathogenesis and therapeutic implications. Eur J Clin Invest 2015;45:609-623. doi: 10.1111/eci.12441.

[14] Ma L, Chua MS, Andrisani O, So S. Epigenetics in hepatocellular carcinoma: an update and future therapy perspectives. World J Gastroenterol 2014;20: 333-345. doi: 10.3748/wjg.v20.i2.333.

[15] Zhang Y. Detection of epigenetic aberrations in the development of hepatocellular carcinoma. Methods Mol Biol 2015;1238:709-731. doi: 10.1007/ 978-1-4939-1804-1_37.

[16] Anwar SL, Lehmann U. DNA methylation, microRNAs, and their crosstalk as potential biomarkers in hepatocellular carcinoma. World J Gastroenterol 2014;20:7894-7913. doi: 10.3748/wjg.v20.i24.7894.

[17] Kojima K, Takata A, Vadnais C, Otsuka M, Yoshikawa T, Akanuma M, et al. MicroRNA122 is a key regulator of $\alpha$-fetoprotein expression and influences the aggressiveness of hepatocellular carcinoma. Nat Commun 2011;2:338. doi: $10.1038 /$ ncomms 1345 .

[18] Fan DN, Tsang FH, Tam AH, Au SL, Wong CC, Wei L, et al. Histone lysine methyltransferase, suppressor of variegation 3-9 homolog 1, promotes hepatocellular carcinoma progression and is negatively regulated by microRNA-125b. Hepatology 2013;57:637-647. doi: 10.1002/hep.26083.

[19] Liu C, Liu L, Shan J, Shen J, Xu Y, Zhang Q, et al. Histone deacetylase 3 participates in self-renewal of liver cancer stem cells through histone modification. Cancer Lett 2013;339:60-69. doi: 10.1016/j.canlet.2013.07.022.

[20] Mansour LA, El Raziky M, Mohamed AA, Mahmoud EH, Hamdy S, El Sayed EH. Circulating hypermethylated RASSF1A as a molecular biomarker for diagnosis of hepatocellular carcinoma. Asian Pac J Cancer Prev 2017;18: 1637-1643. doi: 10.22034/APJCP.2017.18.6.1637.

[21] Kane RC, Farrell AT, Madabushi R, Booth B, Chattopadhyay S, Sridhara R, et al. Sorafenib for the treatment of unresectable hepatocellular carcinoma. Oncologist 2009;14:95-100. doi: 10.1634/theoncologist.2008-0185.

[22] Ibrahim N, Yu Y, Walsh WR, Yang JL. Molecular targeted therapies for cancer: sorafenib mono-therapy and its combination with other therapies (review). Oncol Rep 2012;27:1303-1311. doi: 10.3892/or.2012.1675.

[23] Wilhelm SM, Adnane L, Newell P, Villanueva A, Llovet JM, Lynch M. Preclinical overview of sorafenib, a multikinase inhibitor that targets both Raf and VEGF and PDGF receptor tyrosine kinase signaling. Mol Cancer Ther 2008 7:3129-3140. doi: 10.1158/1535-7163.MCT-08-0013.

[24] Gadaleta-Caldarola G, Infusino S, Divella R, Ferraro E, Mazzocca A, De Rose F, et al. Sorafenib: 10 years after the first pivotal trial. Future Oncol 2015; 11:1863-1880. doi: 10.2217/fon.15.85.

[25] Llovet JM, Ricci S, Mazzaferro V, Hilgard P, Gane E, Blanc JF, et al. Sorafenib in advanced hepatocellular carcinoma. N Engl J Med 2008;359:378-390. doi: 10.1056/NEJMoa0708857.

[26] Johnson PJ. Systemic chemotherapy of liver tumors. Semin Surg Oncol 2000;19:116-124. doi: 10.1002/1098-2388(200009)19:2<116::AIDSSU4>3.0.CO;2-F.

[27] Giglia JL, Antonia SJ, Berk LB, Bruno S, Dessureault S, Finkelstein SE. Systemic therapy for advanced hepatocellular carcinoma: past, present, and future. Cancer Control 2010;17:120-129. doi: 10.1177/ 107327481001700207.

[28] Yeo W, Mok TS, Zee B, Leung TW, Lai PB, Lau WY, et al. A randomized phase III study of doxorubicin versus cisplatin/interferon alpha-2b/doxorubicin/fluorouracil (PIAF) combination chemotherapy for unresectable hepatocellular carcinoma. J Natl Cancer Inst 2005;97:1532-1538. doi: 10.1093/jnci/ dji315.

[29] Hussain SP, Schwank J, Staib F, Wang XW, Harris CC. TP53 mutations and hepatocellular carcinoma: insights into the etiology and pathogenesis of liver cancer. Oncogene 2007;26:2166-2176. doi: 10.1038/sj.onc.1210279.

[30] Ma S, Jiao B, Liu X, Yi H, Kong D, Gao L, et al. Approach to radiation therapy in hepatocellular carcinoma. Cancer Treat Rev 2010;36:157-163. doi: 10. 1016/j.ctrv.2009.11.008.

[31] Cao Y, Fu YL, Yu M, Yue PB, Ge CH, Xu WX, et al. Human augmenter of liver regeneration is important for hepatoma cell viability and resistance to radiation-induced oxidative stress. Free Radic Biol Med 2009;47: 1057-1066. doi: 10.1016/j.freeradbiomed.2009.07.017.

[32] Deng GL, Zeng S, Shen H. Chemotherapy and target therapy for hepatocelIular carcinoma: New advances and challenges. World J Hepatol 2015;7: 787-798. doi: 10.4254/wjh.v7.i5.787.

[33] Fukuhara $H$, Ino $Y$, Todo $T$. Oncolytic virus therapy: A new era of cancer treatment at dawn. Cancer Sci 2016;107:1373-1379. doi: 10.1111/cas. 13027.

[34] Hodi FS, O'Day SJ, McDermott DF, Weber RW, Sosman JA, Haanen JB, et al. Improved survival with ipilimumab in patients with metastatic melanoma. $\mathrm{N}$ Engl J Med 2010;363:711-723. doi: 10.1056/NEJMoa1003466.

[35] Han Y, Chen Z, Yang Y, Jiang Z, Gu Y, Liu Y, et al. Human CD14+ CTLA-4+ regulatory dendritic cells suppress $\mathrm{T}$-cell response by cytotoxic T-lymphocyte antigen-4-dependent IL-10 and indoleamine-2,3-dioxygenase production in hepatocellular carcinoma. Hepatology 2014;59:567-579. doi: 10.1002/ hep. 26694.

[36] Shi F, Shi M, Zeng Z, Qi RZ, Liu ZW, Zhang JY, et al. PD-1 and PD-L1 upregulation promotes CD8(+) T-cell apoptosis and postoperative recurrence in hepatocellular carcinoma patients. Int J Cancer 2011;128:887-896. doi: $10.1002 /$ ijc. 25397.

[37] Li FJ, Zhang Y, Jin GX, Yao L, Wu DQ. Expression of LAG-3 is coincident with the impaired effector function of HBV-specific CD8(+) T cell in HCC patients. Immunol Lett 2013;150:116-122. doi: 10.1016/j.imlet.2012.12.004.

[38] Li H, Wu K, Tao K, Chen L, Zheng $\mathrm{Q}$, Lu X, et al. Tim-3/galectin-9 signaling pathway mediates $\mathrm{T}$-cell dysfunction and predicts poor prognosis in patients with hepatitis B virus-associated hepatocellular carcinoma. Hepatology 2012; 56:1342-1351. doi: 10.1002/hep.25777.

[39] Chen Z, Shen S, Peng B, Tao J. Intratumoural GM-CSF microspheres and CTLA-4 blockade enhance the antitumour immunity induced by thermal ablation in a subcutaneous murine hepatoma model. Int J Hyperthermia 2009;25:374-382. doi: 10.1080/02656730902976807.

[40] Sangro B, Gomez-Martin C, de la Mata M, Iñarrairaegui M, Garralda E, Barrera $\mathrm{P}$, et al. A clinical trial of CTLA-4 blockade with tremelimumab in patients with hepatocellular carcinoma and chronic hepatitis C. J Hepatol 2013;59:81-88. doi: 10.1016/j.jhep.2013.02.022. 
[41] Wang L, Pino-Lagos K, de Vries VC, Guleria I, Sayegh MH, Noelle RJ. Programmed death 1 ligand signaling regulates the generation of adaptive Foxp3+CD4+ regulatory T cells. Proc Natl Acad Sci U S A 2008;105: 9331-9336. doi: 10.1073/pnas.0710441105.

[42] Dong H, Strome SE, Salomao DR, Tamura H, Hirano F, Flies DB, et al. Tumorassociated B7-H1 promotes T-cell apoptosis: a potential mechanism of immune evasion. Nat Med 2002;8:793-800. doi: 10.1038/nm730.

[43] Gao Q, Wang XY, Qiu S], Yamato I, Sho M, Nakajima Y, et al. Overexpression of PD-L1 significantly associates with tumor aggressiveness and postoperative recurrence in human hepatocellular carcinoma. Clin Cancer Res 2009; 15:971-979. doi: 10.1158/1078-0432.CCR-08-1608.

[44] El-Khoueiry AB, Sangro B, Yau T, Crocenzi TS, Kudo M, Hsu C, et al. Nivolumab in patients with advanced hepatocellular carcinoma (CheckMate 040): an open-label, non-comparative, phase $1 / 2$ dose escalation and expansion trial. Lancet 2017;389:2492-2502. doi: 10.1016/S0140-6736 (17)31046-2.

[45] Llovet JM. Updated treatment approach to hepatocellular carcinoma. J Gastroenterol 2005;40:225-235. doi: 10.1007/s00535-005-1566-3.

[46] Bruix J,. Sherman M; American Association for the Study of Liver Diseases. Management of hepatocellular carcinoma: an update. Hepatology 2011;53: 1020-1022. doi: 10.1002/hep.24199.

[47] European Association For The Study Of The Liver; European Organisation For Research And Treatment Of Cancer. EASL-EORTC clinical practice guidelines: management of hepatocellular carcinoma. J Hepatol 2012;56: 908-943. doi: 10.1016/j.jhep.2011.12.001.

[48] Bosch FX, Ribes J, Díaz M, Cléries R. Primary liver cancer: worldwide incidence and trends. Gastroenterology 2004;127:S5-S16. doi: 10.1053/j. gastro.2004.09.011

[49] Cescon M, Cucchetti A, Ravaioli M, Pinna AD. Hepatocellular carcinoma locoregional therapies for patients in the waiting list. Impact on transplantability and recurrence rate. J Hepatol 2013;58:609-618. doi: 10.1016/j. jhep.2012.09.021.

[50] Llovet JM, Bruix J. Systematic review of randomized trials for unresectable hepatocellular carcinoma: Chemoembolization improves survival. Hepatology 2003;37:429-442. doi: 10.1053/jhep.2003.50047.

[51] Maluccio MA, Covey AM, Porat LB, Schubert J, Brody LA, Sofocleous CT, et al. Transcatheter arterial embolization with only particles for the treatment of unresectable hepatocellular carcinoma. J Vasc Interv Radiol 2008;19: 862-869. doi: 10.1016/j.jvir.2008.02.013.

[52] Leung DA, Goin JE, Sickles C, Raskay BJ, Soulen MC. Determinants of postembolization syndrome after hepatic chemoembolization. J Vasc Interv Radiol 2001;12:321-326. doi: 10.1016/S1051-0443(07)61911-3.

[53] Tsochatzis EA, Fatourou EM, Triantos CK, Burroughs AK. Transarterial therapies for hepatocellular carcinoma. Recent Results Cancer Res 2013;190: 195-206. doi: 10.1007/978-3-642-16037-0_13.

[54] Takayasu K, Arii S, Kudo M, Ichida T, Matsui O, Izumi N, et al. Superselective transarterial chemoembolization for hepatocellular carcinoma. Validation of treatment algorithm proposed by Japanese guidelines. J Hepatol 2012;56: 886-892. doi: 10.1016/j.jhep.2011.10.021.

[55] Hsin IF, Hsu CY, Huang $\mathrm{HC}$, Huang $\mathrm{YH}$, Lin $\mathrm{HC}$, Lee RC, et al. Liver failure after transarterial chemoembolization for patients with hepatocellular carcinoma and ascites: incidence, risk factors, and prognostic prediction. J Clin Gastroenterol 2011;45:556-562. doi: 10.1097/MCG.0b013e318210ff17.

[56] Verslype C, Rosmorduc O, Rougier P; ESMO Guidelines Working Group. Hepatocellular carcinoma: ESMO-ESDO Clinical Practice Guidelines for diagnosis, treatment and follow-up. Ann Oncol 2012;23:vii41-vii48. doi: 10. 1093/annonc/mds225.

[57] Curley SA. Radiofrequency ablation versus resection for resectable colorectal liver metastases: time for a randomized trial? Ann Surg Oncol 2008; 15:11-13. doi: 10.1245/s10434-007-9668-1.

[58] European Association for Study of Liver; European Organisation for Research and Treatment of Cancer. EASL-EORTC clinical practice guidelines: management of hepatocellular carcinoma. Eur J Cancer 2012;48:599-641. doi: 10.1016/j.ejca.2011.12.021.

[59] Lu DS, Yu NC, Raman SS, Lassman C, Tong MJ, Britten C, et al. Percutaneous radiofrequency ablation of hepatocellular carcinoma as a bridge to liver transplantation. Hepatology 2005;41:1130-1137. doi: 10.1002/hep. 20688.

[60] Feliu J, Sastre J, Maurel J, Isla D. Hepatocellular and biliary tract carcinomas: SEOM clinical guidelines. Clin Transl Oncol 2011;13:536-544. doi: 10. 1007/s12094-011-0694-x.

[61] Livraghi T, Solbiati L, Meloni MF, Gazelle GS, Halpern EF, Goldberg SN. Treatment of focal liver tumors with percutaneous radio-frequency ablation: complications encountered in a multicenter study. Radiology 2003;226: 441-451. doi: 10.1148/radiol.2262012198.

[62] Crissien AM1, Frenette C1. Current management of hepatocellular carcinoma. Gastroenterol Hepatol (NY) 2014;10:153-161.

[63] Gaiani S, Celli N, Cecilioni L, Piscaglia F, Bolondi L. Review article: percutaneous treatment of hepatocellular carcinoma. Aliment Pharmacol Ther 2003;17:103-110.
[64] Lin SM, Lin CJ, Lin CC, Hsu CW, Chen YC. Randomised controlled trial comparing percutaneous radiofrequency thermal ablation, percutaneous ethanol injection, and percutaneous acetic acid injection to treat hepatocellular carcinoma of $3 \mathrm{~cm}$ or less. Gut 2005;54:1151-1156. doi: 10.1136/ gut.2004.045203.

[65] Vilana R, Bruix J, Bru C, Ayuso C, Solé M, Rodés J. Tumor size determines the efficacy of percutaneous ethanol injection for the treatment of small hepatocellular carcinoma. Hepatology 1992;16:353-357. doi: 10.1002/ hep. 1840160212.

[66] Lencioni R, Cioni D, Crocetti L, Bartolozzi C. Percutaneous ablation of hepatocellular carcinoma: state-of-the-art. Liver Transpl 2004;10:S91-S97. doi: $10.1002 /$ It. 20043.

[67] Shibata T, Iimuro Y, Yamamoto Y, Maetani Y, Ametani F, Itoh K, et al. Small hepatocellular carcinoma: comparison of radio-frequency ablation and percutaneous microwave coagulation therapy. Radiology 2002;223:331-337. doi: 10.1148/radiol.2232010775.

[68] Liang P, Wang Y, Yu X, Dong B. Malignant liver tumors: treatment with percutaneous microwave ablation-complications among cohort of 1136 patients. Radiology 2009;251:933-940. doi: 10.1148/radiol.2513081740.

[69] Madersbacher S, Schatzl G, Djavan B, Stulnig T, Marberger M. Long-term outcome of transrectal high-intensity focused ultrasound therapy for benign prostatic hyperplasia. Eur Urol 2000;37:687-694. doi: 10.1159/000020219.

[70] Gelet A, Chapelon JY, Bouvier R, Souchon R, Pangaud C, Abdelrahim AF, et al. Treatment of prostate cancer with transrectal focused ultrasound: early clinical experience. Eur Urol 1996;29:174-183.

[71] McDannold N, Tempany CM, Fennessy FM, So MJ, Rybicki FJ, Stewart EA, et al. Uterine leiomyomas: MR imaging-based thermometry and thermal dosimetry during focused ultrasound thermal ablation. Radiology 2006; 240:263-272. doi: 10.1148/radiol.2401050717.

[72] Wu F, Wang ZB, Chen WZ, Zou JZ, Bai J, Zhu H, et al. Advanced hepatocellular carcinoma: treatment with high-intensity focused ultrasound ablation combined with transcatheter arterial embolization. Radiology 2005;235: 659-667. doi: 10.1148/radiol.2352030916.

[73] Li YY, Sha WH, Zhou Y], Nie YQ. Short and long term efficacy of high intensity focused ultrasound therapy for advanced hepatocellular carcinoma. J Gastroenterol Hepatol 2007;22:2148-2154. doi: 10.1111/j.1440-1746. 2006.04719.x.

[74] ter Haar G, Rivens I, Chen L, Riddler S. High intensity focused ultrasound for the treatment of rat tumours. Phys Med Biol 1991;36:1495-1501. doi: 10. 1088/0031-9155/36/11/009.

[75] Chen L, Rivens I, ter Haar G, Riddler S, Hill CR, Bensted JP. Histological changes in rat liver tumours treated with high-intensity focused ultrasound. Ultrasound Med Biol 1993;19:67-74. doi: 10.1016/0301-5629(93)90019-K.

[76] Davalos RV, Mir IL, Rubinsky B. Tissue ablation with irreversible electroporation. Ann Biomed Eng 2005;33:223-231. doi: 10.1007/s10439-0058981-8.

[77] Miller L, Leor J, Rubinsky B. Cancer cells ablation with irreversible electroporation. Technol Cancer Res Treat 2005;4:699-705. doi: 10.1177/ 153303460500400615.

[78] Edd JF, Horowitz L, Davalos RV, Mir LM, Rubinsky B. In vivo results of a new focal tissue ablation technique: irreversible electroporation. IEEE Trans Biomed Eng 2006;53:1409-1415. doi: 10.1109/TBME.2006.873745.

[79] Kennedy A, Nag S, Salem R, Murthy R, McEwan AJ, Nutting C, et al. Recommendations for radioembolization of hepatic malignancies using yttrium-90 microsphere brachytherapy: a consensus panel report from the radioembolization brachytherapy oncology consortium. Int J Radiat Oncol Biol Phys 2007;68:13-23. doi: 10.1016/j.ijrobp.2006.11.060.

[80] Salem R, Lewandowski RJ, Mulcahy MF, Riaz A, Ryu RK, Ibrahim S, et al. Radioembolization for hepatocellular carcinoma using Yttrium-90 microspheres: a comprehensive report of long-term outcomes. Gastroenterology 2010;138:52-64. doi: 10.1053/j.gastro.2009.09.006.

[81] Hilgard P, Hamami M, Fouly AE, Scherag A, Müller S, Ertle J, et al. Radioembolization with yttrium-90 glass microspheres in hepatocellular carcinoma: European experience on safety and long-term survival. Hepatology 2010;52:1741-1749. doi: 10.1002/hep.23944.

[82] Pitton MB, Kloeckner R, Ruckes C, Wirth GM, Eichhorn W, Wörns MA, et al. Randomized comparison of selective internal radiotherapy (SIRT) versus drug-eluting bead transarterial chemoembolization (DEB-TACE) for the treatment of hepatocellular carcinoma. Cardiovasc Intervent Radiol 2015; 38:352-360. doi: 10.1007/s00270-014-1012-0.

[83] Wright CL, Werner JD, Tran JM, Gates VL, Rikabi AA, Shah MH, et al. Radiation pneumonitis following yttrium-90 radioembolization: case report and literature review. J Vasc Interv Radiol 2012;23:669-674. doi: 10.1016/j. jvir.2012.01.059.

[84] Riaz A, Lewandowski RJ, Kulik LM, Mulcahy MF, Sato KT, Ryu RK, et al. Complications following radioembolization with yttrium-90 microspheres: a comprehensive literature review. J Vasc Interv Radiol 2009;20:11211130; quiz 1131. doi: 10.1016/j.jvir.2009.05.030.

[85] Atassi B, Bangash AK, Lewandowski RJ, Ibrahim S, Kulik L, Mulcahy MF, et al. Biliary sequelae following radioembolization with Yttrium-90 
microspheres. J Vasc Interv Radiol 2008;19:691-697. doi: 10.1016/j.jvir 2008.01.003.

[86] Liem MS, Poon RT, Lo CM, Tso WK, Fan ST. Outcome of transarterial chemoembolization in patients with inoperable hepatocellular carcinoma eligible for radiofrequency ablation. World J Gastroenterol 2005;11:4465-4471. doi: $10.3748 /$ wjg.v11.i29.4465.

[87] Pawlik TM, Reyes DK, Cosgrove D, Kamel IR, Bhagat N, Geschwind JF. Phase II trial of sorafenib combined with concurrent transarterial chemoembolization with drug-eluting beads for hepatocellular carcinoma. J Clin Oncol 2011;29:3960-3967. doi: 10.1200/JCO.2011.37.1021.

[88] Bai W, Wang Y], Zhao Y, Qi XS, Yin ZX, He CY, et al. Sorafenib in combination with transarterial chemoembolization improves the survival of patients with unresectable hepatocellular carcinoma: a propensity score matching study. J Dig Dis 2013;14:181-190. doi: 10.1111/1751-2980.12038.

[89] Zhao Y, Wang WJ, Guan S, Li HL, Xu RC, Wu JB, et al. Sorafenib combined with transarterial chemoembolization for the treatment of advanced hepatocellular carcinoma: a large-scale multicenter study of 222 patients. Ann Oncol 2013;24:1786-1792. doi: 10.1093/annonc/mdt072.

[90] Leksell L, Lindquist C, Adler JR, Leksell D, Jernberg B, Steiner L. A new fixation device for the Leksell stereotaxic system. Technical note. J Neurosurg 1987;66:626-629. doi: 10.3171/jns.1987.66.4.0626.

[91] Goyal K, Einstein D, Yao M, Kunos C, Barton F, Singh D, et al. Cyberknife stereotactic body radiation therapy for nonresectable tumors of the liver: preliminary results. HPB Surg 2010;2010:309780. doi: 10.1155/2010/ 309780.

[92] Lartigau E, Mirabel X, Prevost B, Lacornerie T, Dubus F, Sarrazin T. Extracranial stereotactic radiotherapy: preliminary results with the CyberKnife. Onkologie 2009;32:209-215. doi: 10.1159/000200929.

[93] Stintzing S, Hoffmann RT, Heinemann V, Kufeld M, Rentsch M, Muacevic A Radiosurgery of liver tumors: value of robotic radiosurgical device to treat liver tumors. Ann Surg Oncol 2010;17:2877-2883. doi: 10.1245/s10434010-1187-9.

[94] Stintzing S, Grothe A, Hendrich S, Hoffmann RT, Heinemann V, Rentsch M, et al. Percutaneous radiofrequency ablation (RFA) or robotic radiosurgery (RRS) for salvage treatment of colorectal liver metastases. Acta Oncol 2013;52:971-977. doi: 10.3109/0284186X.2013.766362.

[95] Clavien PA, Petrowsky H, DeOliveira ML, Graf R. Strategies for safer liver surgery and partial liver transplantation. N Engl J Med 2007;356: 1545-1559. doi: 10.1056/NEJMra065156.

[96] Shi JH, Line PD. Effect of liver regeneration on malignant hepatic tumors. World J Gastroenterol 2014;20:16167-16177. doi: 10.3748/wjg.v20.i43. 16167.

[97] Cucchetti A, Vitale A, Cescon M, Gambato M, Maroni L, Ravaioli M, et al. Can liver transplantation provide the statistical cure? Liver Transpl 2014;20: 210-217. doi: 10.1002/It.23783.

[98] Mazzaferro V, Regalia E, Doci R, Andreola S, Pulvirenti A, Bozzetti F, et al. Liver transplantation for the treatment of small hepatocellular carcinomas in patients with cirrhosis. N Engl J Med 1996;334:693-699. doi: 10.1056/ NEJM199603143341104

[99] Wörns MA, Galle PR. Future perspectives in hepatocellular carcinoma Dig Liver Dis 2010;42:S302-S309. doi: 10.1016/S1590-8658(10)60521-X

[100] Mazzaferro V, Bhoori S, Sposito C, Bongini M, Langer M, Miceli R, et al. Milan criteria in liver transplantation for hepatocellular carcinoma: an evidencebased analysis of 15 years of experience. Liver Transpl 2011;17:S44-S57. doi: $10.1002 /$ It.22365.

[101] Chan SC, Fan ST. Selection of patients of hepatocellular carcinoma beyond the Milan criteria for liver transplantation. Hepatobiliary Surg Nutr 2013;2 84-88. doi: 10.3978/j.issn.2304-3881.2012.12.04.

[102] Yao FY, Ferrell L, Bass NM, Watson J], Bacchetti P, Venook A, et al. Liver transplantation for hepatocellular carcinoma: expansion of the tumor size limits does not adversely impact survival. Hepatology 2001;33: 1394-1403. doi: 10.1053/jhep.2001.24563.
[103] Gandini S, Botteri E, Iodice S, Boniol M, Lowenfels AB, Maisonneuve $P$, et al. Tobacco smoking and cancer: a meta-analysis. Int J Cancer 2008;122: 155-164. doi: 10.1002/ijc.23033.

[104] DuBay D, Sandroussi C, Sandhu L, Cleary S, Guba M, Cattral MS, et al. Liver transplantation for advanced hepatocellular carcinoma using poor tumor differentiation on biopsy as an exclusion criterion. Ann Surg 2011;253: 166-172. doi: 10.1097/SLA.0b013e31820508f1.

[105] Foster JH, Berman MM. Solid liver tumors. Major Probl Clin Surg 1977;22: $1-342$.

[106] Llovet JM, Schwartz M, Mazzaferro V. Resection and liver transplantation for hepatocellular carcinoma. Semin Liver Dis 2005;25:181-200. doi: 10. 1055/s-2005-871198.

[107] Belghiti J, Hiramatsu K, Benoist S, Massault P, Sauvanet A, Farges O. Seven hundred forty-seven hepatectomies in the 1990s: an update to evaluate the actual risk of liver resection. J Am Coll Surg 2000;191:38-46. doi: 10.1016/S1072-7515(00)00261-1.

[108] Wörns MA, Weinmann A, Schuchmann M, Galle PR. Systemic therapies in hepatocellular carcinoma. Dig Dis 2009;27:175-188. doi: 10.1159/ 000218351

[109] Bruix J, Boix L, Sala M, Llovet JM. Focus on hepatocellular carcinoma. Cancer Cell 2004;5:215-219. doi: 10.1016/S1535-6108(04)00058-3.

[110] Wong R, Frenette C. Updates in the management of hepatocellular carcinoma. Gastroenterol Hepatol (N Y) 2011;7:16-24.

[111] Ishizawa $T$, Hasegawa $K$, Aoki T, Takahashi M, Inoue $Y$, Sano K, et al. Neither multiple tumors nor portal hypertension are surgical contraindications for hepatocellular carcinoma. Gastroenterology 2008;134:1908-1916. doi: 10.1053/j.gastro.2008.02.091.

[112] Oldhafer KJ, Donati M, Jenner RM, Stang A, Stavrou GA. ALPPS for patients with colorectal liver metastases: effective liver hypertrophy, but early tumor recurrence. World J Surg 2014;38:1504-1509. doi: 10.1007/ s00268-013-2401-2.

[113] Govil S. Rapid improvement in liver volume induced by portal vein ligation and staged hepatectomy: the ALPPS procedure. HPB (Oxford) 2012;14: 874. doi: 10.1111/j.1477-2574.2012.00573.x.

[114] Cavaness KM, Doyle MB, Lin Y, Maynard E, Chapman WC. Using ALPPS to induce rapid liver hypertrophy in a patient with hepatic fibrosis and portal vein thrombosis. J Gastrointest Surg 2013;17:207-212. doi: 10.1007/ s11605-012-2029-9.

[115] Schnitzbauer AA, Lang SA, Goessmann H, Nadalin S, Baumgart J, Farkas $\mathrm{SA}$, et al. Right portal vein ligation combined with in situ splitting induces rapid left lateral liver lobe hypertrophy enabling 2-staged extended right hepatic resection in small-for-size settings. Ann Surg 2012;255:405-414. doi: $10.1097 /$ SLA.0b013e31824856f5.

[116] Bertens KA, Hawel J, Lung K, Buac S, Pineda-Solis K, Hernandez-Alejandro R. ALPPS: challenging the concept of unresectability-a systematic review. Int J Surg 2015;13:280-287. doi: 10.1016/j.ijsu.2014.12.008.

[117] Ielpo B, Quijano $Y$, Vicente E. Pearls and pitfalls on ALPPS procedure: new complications in a new technique. Updates Surg 2014;66:159-161. doi: 10.1007/s13304-014-0249-0

[118] Schadde E, Raptis DA, Schnitzbauer AA, Ardiles V, Tschuor C, Lesurtel M, et al. Prediction of mortality after ALPPS stage-1: an analysis of 320 patients from the international ALPPS registry. Ann Surg 2015;262:780785; discussion 785-786. doi: 10.1097/SLA.0000000000001450.

[119] Alvarez FA, Ardiles V, Sanchez Claria R, Pekolj J, de Santibañes E. Associating liver partition and portal vein ligation for staged hepatectomy (ALPPS): tips and tricks. J Gastrointest Surg 2013;17:814-821. doi: 10.1007/ s11605-012-2092-2.

[120] D'Haese JG, Neumann J, Weniger M, Pratschke S, Björnsson B, Ardiles V, et al. Should ALPPS be used for liver resection in intermediate-stage HCC? Ann Surg Oncol 2016;23:1335-1343. doi: 10.1245/s10434-015-5007-0. 